\title{
Static and Fatigue Analysis of the Front Draft Lugs of a Railroad Tank-Car Using FEM
}

\author{
J. O. Trejo-Escandón ${ }^{1}$, A. Leyva-Díaz, J. M. Sandoval-Pineda, P. A. Tamayo-Meza, L. A. Flores-Herrera. \\ Instituto Politécnico Nacional, Escuela Superior de Ingeniería Mecánica y Eléctrica, Sección de Estudios de Posgrado \\ e Investigación, Avenida de las Granjas No. 682, Col. Santa Catarina, 02250 Azcapotzalco, DF, México.
}

\begin{abstract}
In this work the main results of a static and fatigue analysis performed by means of a computational model of a Tank-Car are presented. The tensile load (draft) is the more continuous condition presented during typical service situations, and is directly applied over the front draft lugs when the train starts its movement. In this sense, a three-dimensional finite element analysis of the wagon is carried out in the ANSYS Workbench platform. The static loads are applied in orden to estimate the fatigue life of the lugs. The material properties and boundary conditions were applied directly in accordance with the guidelines set out by the American Association of Railroads (AAR). The results of this analysis can be a useful tool for designers of railway equipment and to improve the designs safety.
\end{abstract}

Keywords- Draft lugs, Fatigue Analysis, FEA, Static load, TankCar.

\section{INTRODUCTION}

The movement of railway equipment involves heavy pulling and pushing forces to move the weight of the cars as the train moves. To ensure that the car and locomotive can accept this movement without causing damage to the equipment and/or lading, the equipment must have a system to absorb this punishment. However, some equipment such as front and rear lugs must be designed to withstand a certain amount of load [1].

Since 1865, the railroad tank cars have been used for the transport of fluids, mainly hydrocarbons [2]. The railroad, tank car, and different industries have worked together with the government to develop and improve safety design standards for tank cars. For this reason in 1934 the American Association of Railroads (AAR), which is responsible to monitor and coordinate current safety standards and design of rail cars in North America was created [3].

The design of railroad tank cars is subject to structural and performance requirements and constrained by weight Sometimes they have tried to improve the design safety by increasing tank thickness and adding various protective features, but in general these modifications increase the weight and cost of the car $[4,5]$.

The Finite Element Method (FEM) is generally used to analyze complex mechanical structures [6, 7]. Miele and Rice [8] performed one of the first investigations using the FEM to find the stress distribution in two different models of tank cars. In this sense, note that the tank shell is the main structural member of the car, because any tensile or compressive force occurring in service are transmitted through this body. Domagala and Lisowski [9] indicate that Fluid Structure Interaction simulation represents a very efficient tool to design mobile tanks, especially under dynamic loading. Shortly after, Patel, et. al., [10] conducted a research to determine the fatigue life of rail joint using ANSYS ${ }^{\circledR}$.

Although the AAR [11] request that the majority of the tests realized to tank cars are static, the mechanical behavior under static load and estimates of fatigue in critical areas have been studied less often. In this sense, there is little research on the subject.

The main objective of this paper is to present a methodology for the numerical analysis of a computational model of a tank car subjected to draft load scenarios, and to estimate the fatigue life of the charged members (front draft lugs).

\section{THEORETICAL FRAMEWORK}

\section{A. Tank car classification and specifications}

A tank car is a type of railroad freight car whose body is made up of a horizontal tank (shell) designed to transport chemicals, petroleum products, and other bulk liquids and compressed gases $[11,12]$. As shown in Fig. 1, the cylindrical body or shell is sealed at its ends by means of hemispherical or ellipsoidal heads.

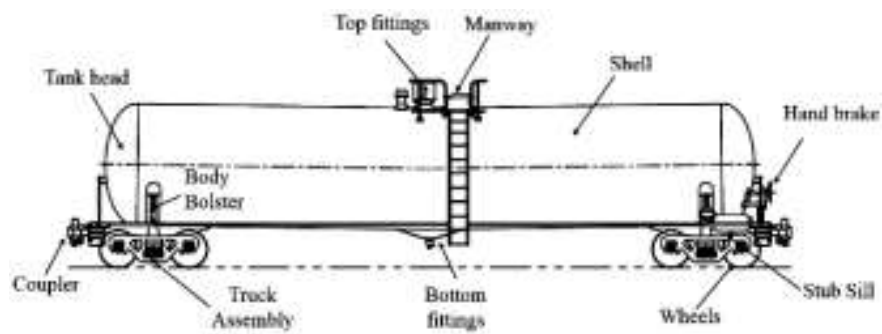

Fig. 1 Principal design elements of a regular Tank-Car.

In Fig, 2, the principal components of the stub zone are shown. 


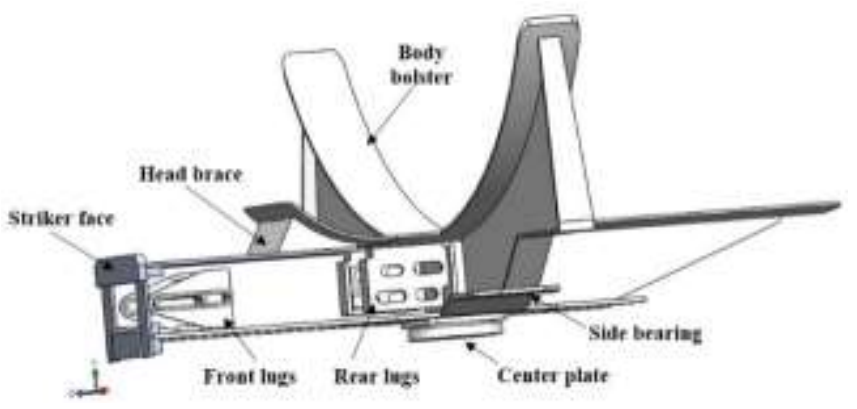

Fig. 2 Principal components of the stub-bolster of a regular Tank-Car.

\section{B. Formulations for linear problems of elasticity}

For linear elastic materials, the stress-strain relations come from the generalized Hooke's law. For isotropic materials, the two material properties are Young's modulus, E and Poisson's ratio, $v$. These relationships are given by:

$$
\varepsilon_{x}+\varepsilon_{y}+\varepsilon_{z}=\frac{(1-2 v)}{E}\left(\sigma_{x}+\sigma_{y}+\sigma_{z}\right)
$$

According to [13], substituting for $\left(\sigma_{y}+\sigma_{z}\right)$ in $(1)$, the resulted inverse relations are:

$$
\{\sigma\}=[D]\{\varepsilon\}
$$

where $\{\sigma\}=\left[\begin{array}{llllll}\sigma_{x} & \sigma_{y} & \sigma_{z} & \sigma_{x y} & \sigma_{y z} & \sigma_{z x}\end{array}\right]^{T}$, is called column vector of stress, $\{\varepsilon\}$ is the column vector for each corresponding strain, which can be expressed as:

$$
\{\varepsilon\}=\left[\begin{array}{llllll}
\varepsilon_{x} & \varepsilon_{y} & \varepsilon_{z} & \varepsilon_{x y} & \varepsilon_{y z} & \varepsilon_{z x}
\end{array}\right]^{T}
$$

finally, $[D]$ is the symmetric $(6 \times 6)$ material matrix given by:

$$
\begin{gathered}
\quad D= \\
\times \quad \frac{E}{(1+v)(1-2 v)} \times \\
\times\left[\begin{array}{cccccc}
1-v & v & v & 0 & 0 & 0 \\
v & 1-v & v & 0 & 0 & 0 \\
v & v & 1-v & 0 & 0 & 0 \\
0 & 0 & 0 & 0.5-v & 0 & 0 \\
0 & 0 & 0 & 0 & 0.5-v & 0 \\
0 & 0 & 0 & 0 & 0 & 0.5-v
\end{array}\right]
\end{gathered}
$$

\section{MODELLING}

A non-pressure, general purpose, stub sill tank-car was geometrically modelled using CAD, the result can be seen in Fig. 3, whose principal characteristics are described in Table I.

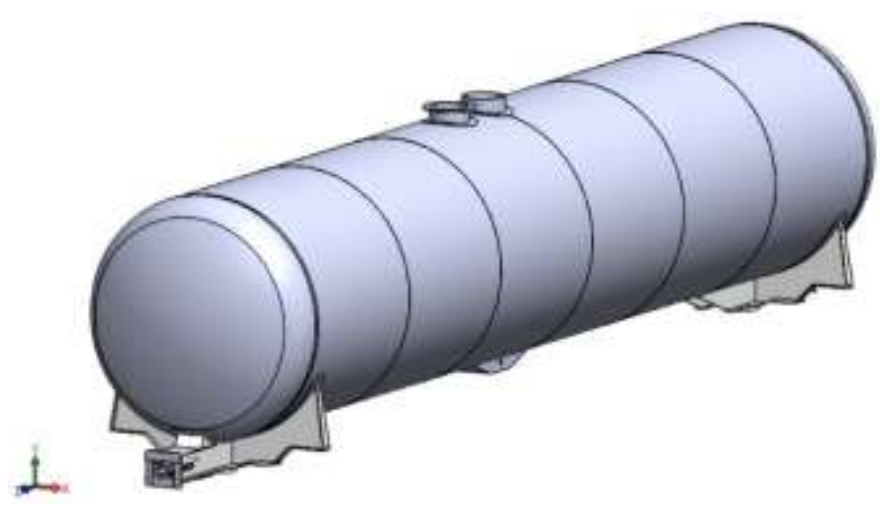

Fig. 3 Isometric view of the model

TABLE I

PRINCIPAL GEOMETRIC CHARACTERISTICS OF THE MODEL PROPOSED

\begin{tabular}{|lc|}
\hline Shell length & $14.83 \mathrm{~m}$ \\
\hline Diameter of head & $3 \mathrm{~m}$ \\
\hline Thickness of shell and heads & $0.0127 \mathrm{~m}$ \\
\hline Stub length & $3.07 \mathrm{~m}$ \\
\hline $\begin{array}{l}\text { Distance between center } \\
\text { plates }\end{array}$ & $14 \mathrm{~m}$ \\
\hline Maximum capacity & 150,0001 \\
\hline Gross rail load & $129,727 \mathrm{~kg}$ \\
\hline
\end{tabular}

\section{A. Definition of materials}

ASTM TC-128B steel was selected as the material of the structure because currently most tank cars are currently made with this material [14], whose properties are shown in Table II.

TABLE II

TC-128B MATERIAL PROPERTIES

\begin{tabular}{|l|c|}
\hline \multicolumn{1}{|c|}{ Mechanical Property } & Value \\
\hline Young's modulus, $E$ & $206,842.773 \mathrm{MPa}$ \\
\hline Poisson's ratio, $v$ & 0.3 \\
\hline Yield strength & $344.738 \mathrm{MPa}$ \\
\hline Tensile strength & $558.475 \mathrm{MPa}$ \\
\hline Weight density & $7,916.453 \mathrm{~kg} / \mathrm{m}^{3}$ \\
\hline
\end{tabular}


A36 structural steel was defined as material of the lugs because according to regulations, these additions must be simulated numerically with this material. In Table III are shown their main properties.

TABLE III

A36 STRUCTURAL STEEL MATERIAL PROPERTIES

\begin{tabular}{|l|c|}
\hline \multicolumn{1}{|c|}{ Mechanical Property } & Value \\
\hline Young's modulus, $E$ & $200 \mathrm{GPa}$ \\
\hline Poisson's ratio, $v$ & 0.3 \\
\hline Yield strength & $250 \mathrm{MPa}$ \\
\hline Tensile strength & $460 \mathrm{MPa}$ \\
\hline Weight density & $7850 \mathrm{~kg} / \mathrm{m}^{3}$ \\
\hline
\end{tabular}

\section{FINITE ELEMENT MODEL DESCRIPTION}

The model was exported to the ANSYS Workbench platform to be solved and discretized in finite elements. It was necessary the simplification of the geometry and the establishment of contacts between the elements that integrate it. The weld zone was considered with simple contacts.

\section{A. Meshing}

The tank was modelled with shell elements, while the longitudinal members (stubs) and other elements were modelled from solid elements. Likewise a mass point of 825 $\mathrm{kg}$ was added on each stub to simulate the weight causing some typical attachments which are placed in that area. Finally, the model was constituted according to the values presented in Table IV.

TABLE IV

MESHING CHARACTERISTICS

\begin{tabular}{|l|c|}
\hline Nodes & 424456 \\
\hline Elements & 106209 \\
\hline Skewness average & $0.39(\mathrm{Good})$ \\
\hline Orthogonal quality average & 0.70 (Very good) \\
\hline
\end{tabular}

The Hex Dominant Method was selected as the method of meshing to achieve a more orderly and better distributed mesh. Figures. 4 and 5 show the finite element model of the tank-car.

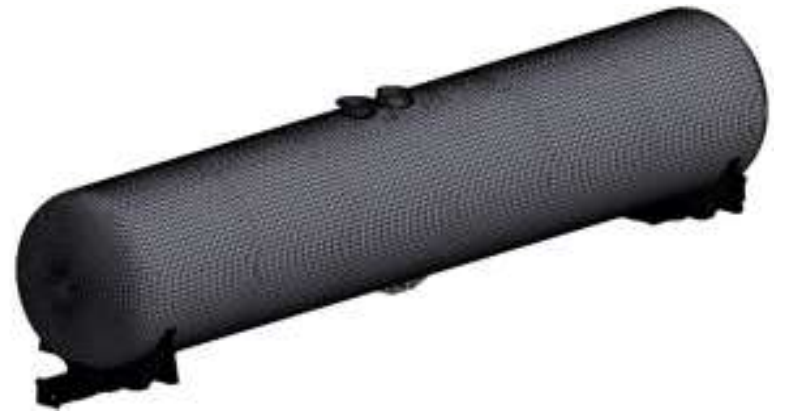

Fig. 4 Isometric view of the Finite Element Model

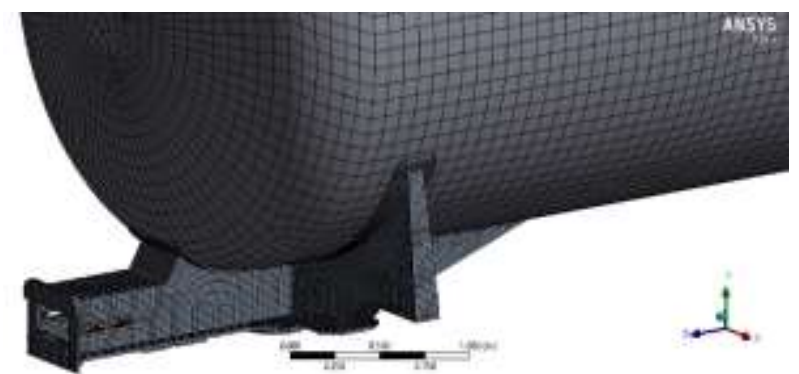

Fig. 5 Close view of the mesh in the Stub zone

\section{BOUNDARY CONDITIONS}

All the boundary conditions were applied strictly as per the guidelines made available by the AAR in their Manual of Standards and Recommended Practices [11]. Hydrostatic pressure was used to simulate the conditions of a full tank, the pressure was directly applied to the inner walls of the shell with a fluid density of $1000 \mathrm{~kg} / \mathrm{m}^{3}$, which is slightly larger than of the tank cars intended for the transportation of hydrocarbons. The boundary conditions provided by the trucks were simulated by using simple supports at each end.

\section{A. Draft load case}

The car structure shall be designed to sustain a draft (tensile) drawbar and/or train-action load of $1557 \mathrm{kN}$ applied on the front draft lugs at each end of the car along the nominal centerline of the couplers. In Figs. 6 and 7 can be seen a schematic representation of this loading condition.

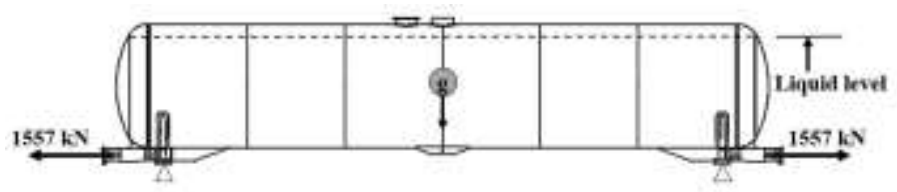

Fig. 6 Schematic representation of the draft condition 


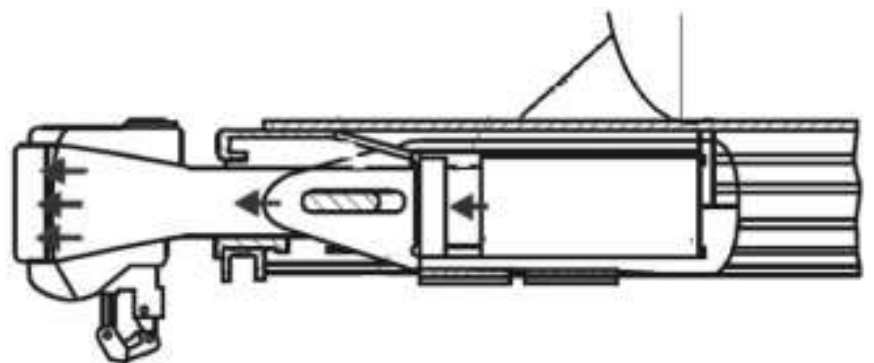

Fig. 7 Schematic representation of the boundary condition over the front draft lugs [1]

\section{B. Fatigue analysis}

For the fatigue analysis the ANSYS Fatigue Tool module was used, in this sense, the Zero-Based constant amplitude loaded was selected.

The material and strain life properties of the front draft lug used in this fatigue analysis are listed in Table III. Fig. 8 indicates the strain life curve of A36 structural steel. VonMises stresses obtained from finite element analysis were utilized in fatigue life calculations.

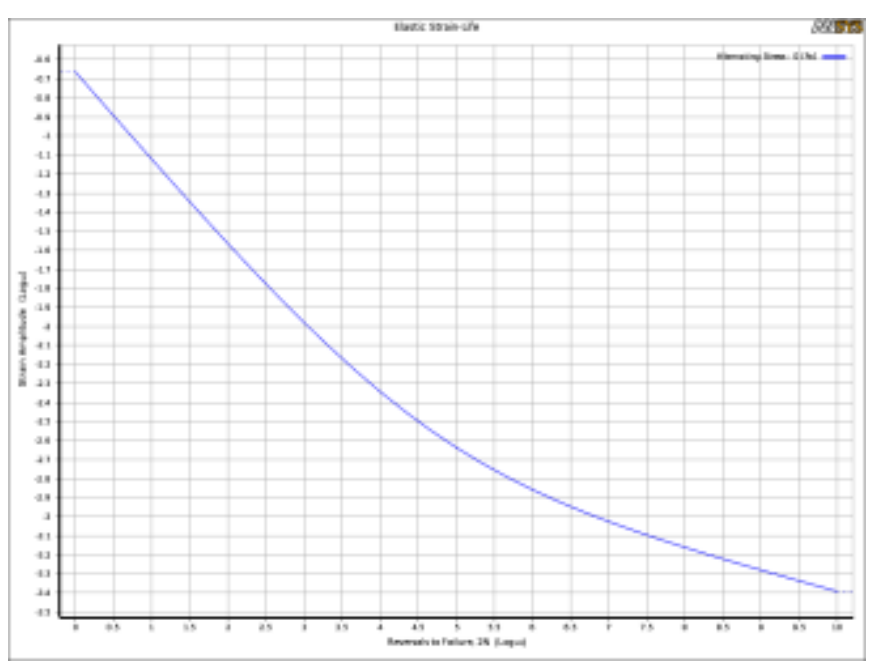

Fig. 8 Strain-life curve for A36 structural steel

\section{RESULTS AND DISCUSSION}

In this work, results obtained for the static and fatigue analysis of the draft lug of a tank-car are analyzing following parameters:

- Von-Mises stresses of the static analysis

- Fatigue life of the front draft lugs.

- Fatigue factor of safety at a specified design life of 1 e6 cycles.

\section{A. Static results}

Fig. 9 shows the total deformation for the case of filled tank, the maximum deformations occur in the bottom area of the tank -y direction, while in the stub zone and heads the deformations are smaller and in positive direction.
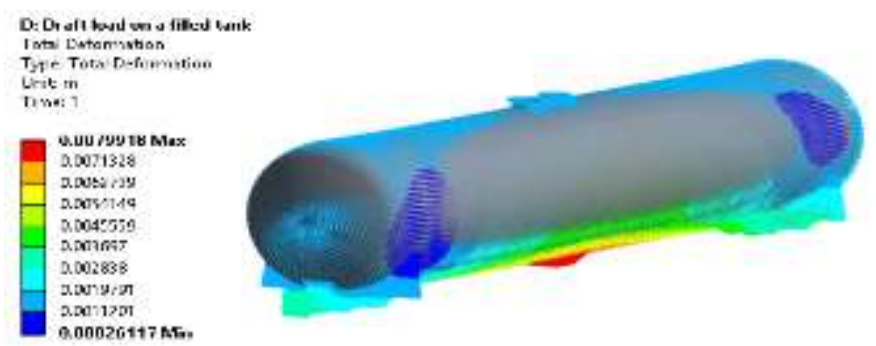

Fig.9 Deformation vector plot

In the case of the stress distribution, the maximums appeared at an angled joining area of the front draft lugs. This high stress concentration due to the weld was not explicitly modelled according to the recommendations of the standard [11], this is normal and is rarely present in real conditions. The Von-Mises stress distribution on the tank shell was relatively acceptable and do not exceed the yield strength of the material. In Figs. 10 and 11 the principal results are presented.

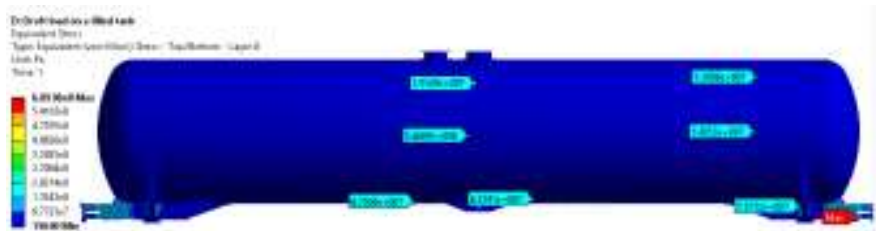

Fig.10 Von-Mises stress distribution over the tank

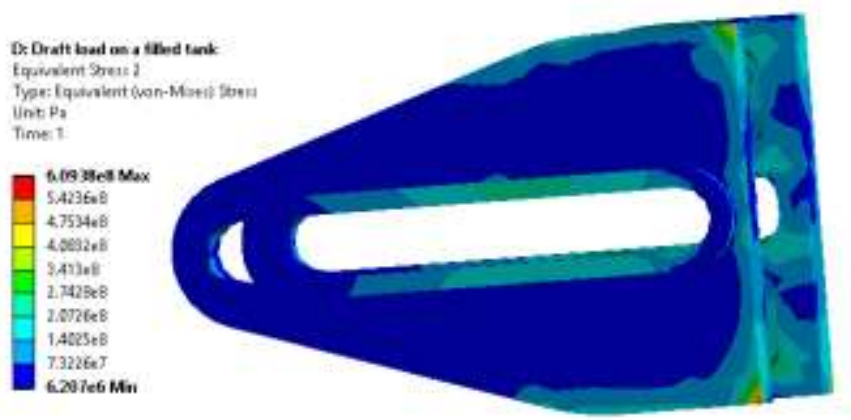

Fig.11 Von-Mises stress distribution on the front draft lugs.

\section{B. Fatigue results}

Fig. 12 shows the estimated life for the front draft lugs due to static loads. A total of 99352 cycles are necessary to initiate failure in the front draft lugs of a tank-car. 


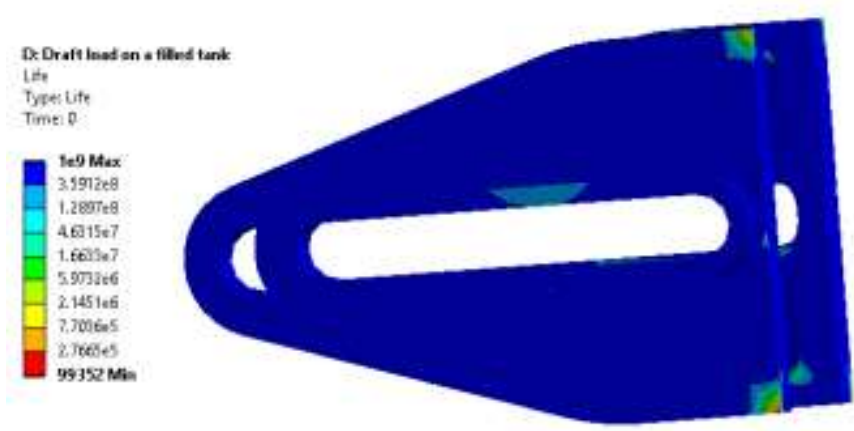

Fig.12 Estimated life for the front draft lugs

A safety factor of 0.71 was calculated for the most critical zones of the lugs. The results of this analysis can observed in Fig. 13.

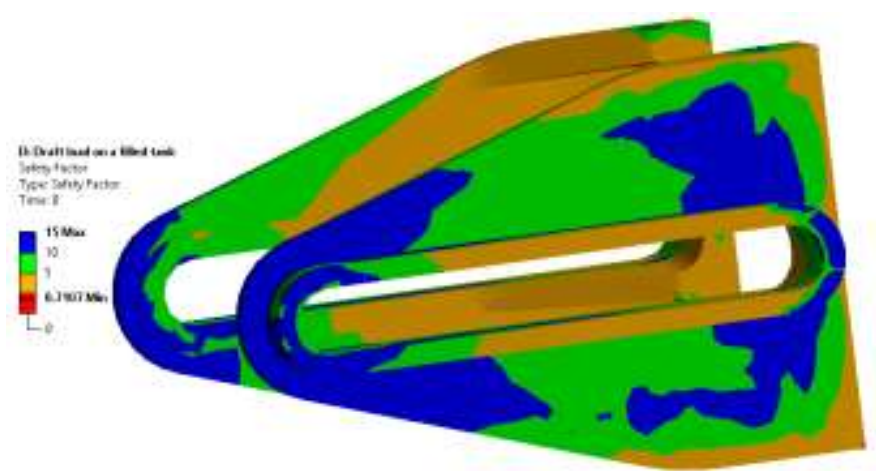

Fig.13 Safety factor in the front draft lugs

Fig. 14. Indicates failure life of the draft lugs according to the load limit (lowest case is $1 \%$ of the actual load, highest case is $150 \%$ of the actual load).

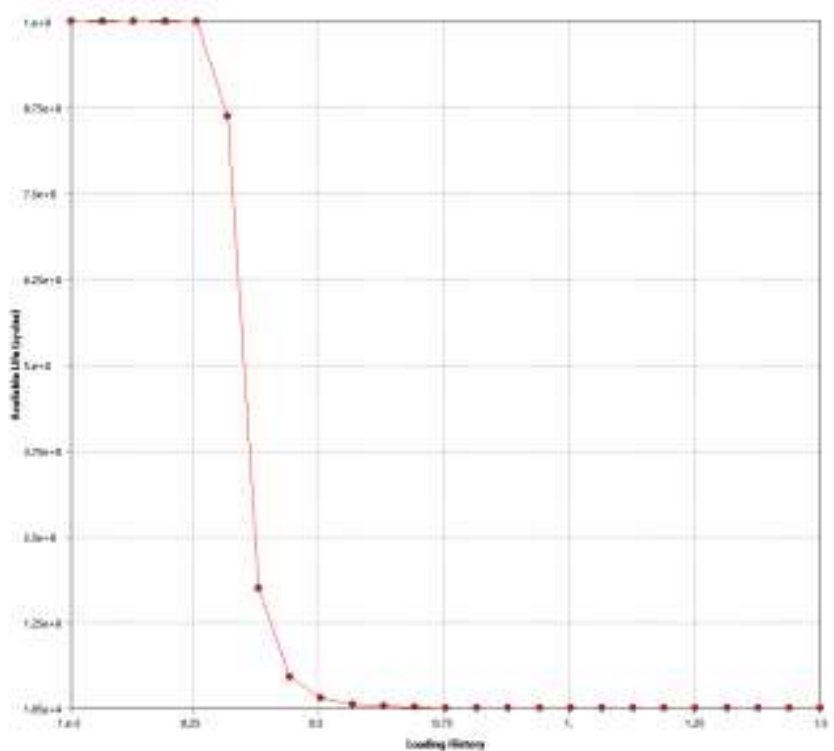

Fig.14 Life diagram of the draft lugs between different loading variations 1 $150 \%$ (fatigue sensitivity)

\section{CONCLUSIONS}

The method described in this research may be used to estimate the fatigue life of the draft lugs of a railroad tank.car. It also can be used to validate new freight car designs. This analysis methodology is appropriate for obtaining fatigue analysis of railcars designs, especially for tank-cars. In any ways experimental work is required.

The results of the Finite Element Analysis confirm that the shell of a Tank-Car is the primary structural element, since any static force incurred in service is transmitted through the tank shell. The most critical site, in terms of stress concentration tends to be the welded region where the front draft lugs are welded to the stub sill.

The fatigue life estimated suggest that the lugs should be changed after about 99300 charge cycles, ensuring the integrity and security of the units. Similarly, the results of the deformation analysis are within the normal range. Therefore it is concluded that tank-cars represent a suitable and efficient transport of hydrocarbons.

\section{ACKNOWLEDGMENT}

The authors acknowledge to the Instituto Politécnico Nacional, Escuela Superior de Ingeniería Mecánica y Eléctrica Unidad Azcapotzalco and the Consejo Nacional de Ciencia y Tecnología (CONACYT) in México for their support and facilities provided for the development of this research.

\section{REFERENCES}

[1] Wabtec Corporation, Freight Car Draft Arrangements, Wabtec Corporation, USA, 2003.

[2] F. J. Heller, "Evolution of tank car design through engineering," Proceedings of the 1970 Annual ASME Petroleum Conference, Denver, Colorado, 1970

[3] C. P. L. Barkan, M. R. Saat, F. González, and T. T. Treichel, "How science and engineering are reducing risk of rail transport of hazardous materials," Cooperative Research in Tank Car Safety Design in Railroads and Research sharing track, TR NEWS, no. 286, pp. 12-19, May-June 2013.

[4] M. R. Saat and C. P. L. Barkan, "Generalized railway tank safety design optimization for hazardous materials transport: Addressing the trade-off between transportation efficiency and safety," Journal of Hazardous Materials, vol. 189, pp. 62-68, 2011.

[5] C. P. L. Barkan, T. T. Treichel, and G. W. Widell, "Reducing hazardous materials releases from railroad tank car safety events," Transp. Res. Rec. 1707, pp. 27-34, 2000.

[6] C. A. Duarte, I. Babuška, and J. T. Oden, "Generalized finite element methods for three-dimensional structural mechanics problems," Computers \& Structures, vol. 77, pp. 215-232, 2000.

[7] G. Dhatt, G. Touzot, and E. Lefrançois, Finite Element Method. Numerical Methods Series, John Wiley \& Sons, Inc., 1st edition, London, 2012.

[8] . R. Miele and R. C. Rice, Stress Analysis of Stub Sill Tank Cars, Final Report, to Volpe National Transportation Systems Center Research and Special Programs Administration U.S. Department of Transportation, Columbus, Ohio, December 1993. 
[9] M. Domagala, and E. Lisowski, "Interaction of liquid motion on mobile tank structure," Journal of KONES Powertrain and Transport, vol. 18, no. 3, pp. 67-71, 2011.

[10] S. Patel, V. Kumar, and R. Nareliya, "Fatigue analysis of rail joint using finite element method", International Journal of Research in Engineering and Technology, Vol. 2, no. 1, pp.80-84,2013.

[11] Association of American Railroads (AAR), Section C-III Specifications for tank cars, in: Manual of Standards and Recommended Practices, Association of American Railroads, Washington, DC, 2007.
[12] C. F. Schulte, Dictionary of railway track terms, Simmons-Boardman Books, Inc., ed 3rd, 2003.

[13] C. R. Alavala, Finite Element Methods: basic concepts and applications, PHI Learning Private Limited, pp. 3-20, New Delhi, 2009.

[14] M. Carolan, B. Talamini, and D. Tyrell, "Update on ongoing tank car crashworthiness research predicted performance and fabrication approach," Proceedings of 2008 IEEE/ASME Joint Rail Conference, Wilmington, Delaware, April 22-23, 2008. 